\title{
Budget Impact Analysis of Molecular Lymph Node Staging Versus Conventional Histopathology Staging in Colorectal Carcinoma
}

\author{
Sherley Diaz-Mercedes ${ }^{1}$ (1) - Ivan Archilla ${ }^{1}$ Jordi Camps ${ }^{2,8} \cdot$ Antonio de Lacy $^{3} \cdot$ Iñigo Gorostiaga ${ }^{4} \cdot$ Dulce Momblan $^{3}$.

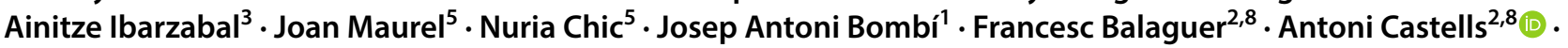

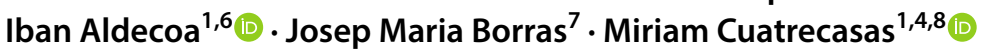

Published online: 21 May 2019

(c) The Author(s) 2019

\begin{abstract} metastases. patients in the Spanish National Health System (NHS). than $€ 19$ million for the NHS over the 3-year time horizon.

\section{Introduction}

Colorectal cancer (CRC) is the third most common cancer worldwide, with nearly 1.8 million newly diagnosed cases in 2018, according to Globocan 2018 estimates [1]. In Spain, CRC was the most prevalent type of cancer in 2017, with
\end{abstract}

Background The presence of lymph node (LN) metastasis is a critical prognostic factor in colorectal cancer (CRC) patients and is also an indicator for adjuvant chemotherapy. The gold standard (GS) technique for LN diagnosis and staging is based on the analysis of haematoxylin and eosin (H\&E)-stained slides, but its sensitivity is low. As a result, patients may not be properly diagnosed and some may have local recurrence or distant metastases after curative-intent surgery. Many of these diagnostic and treatment problems could be avoided if the one-step nucleic acid amplification assay (OSNA) was used rather than the GS technique. OSNA is a fast, automated, standardised, highly sensitive, quantitative technique for detecting LN

Objectives The aim of this study was to assess the budget impact of introducing OSNA LN analysis in early-stage CRC

Methods A budget impact analysis comparing two scenarios (GS vs. OSNA) was developed within the Spanish NHS framework over a 3-year time frame (2017-2019). The patient population consisted of newly diagnosed CRC patients undergoing surgical treatment, and the following costs were included: initial surgery, pathological diagnosis, staging, follow-up expenses, systemic treatment and surgery after recurrence. One- and two-way sensitivity analyses were performed.

Results Using OSNA instead of the GS would have saved $€ 1,509,182, € 6,854,501$ and $€ 10,814,082$ during the first, second and third years of the analysis, respectively, because patients incur additional costs in later years, leading to savings of more

Conclusions Introducing OSNA in CRC LN analysis may represent not only an economic benefit for the NHS but also a clinical benefit for CRC patients since a more accurate staging could be performed, thus avoiding unnecessary treatments.

Sherley Diaz-Mercedes and Ivan Archilla contributed equally.

Iban Aldecoa and Miriam Cuatrecasas contributed equally.

Electronic supplementary material The online version of this article (https://doi.org/10.1007/s40258-019-00482-7) contains supplementary material, which is available to authorized users.

Miriam Cuatrecasas

mcuatrec@clinic.cat

Extended author information available on the last page of the article
34,331 new cases diagnosed that year, and was the second leading cause of death by cancer in 2016 [2]. Over the last 30 years, improvements in early diagnosis and treatment have doubled the 5-year survival of CRC patients [3-6]; however, these improved outcomes have been costly and imposed a higher economic burden on health systems [7]. In 2016, the mean cost per CRC patient in Spain ranged from $€ 9634$ among in situ tumours to $€ 41,550$ for stage III patients. Over this same period, the global mean cost per patient was $€ 28,741$ [7].

Unless there are other factors that hinder the surgical procedure, surgical excision is the main approach for nondisseminated CRC [8]. The presence of lymph node (LN) metastasis is a critical prognostic factor for patients with $\mathrm{CRC}$, and also determines the need for adjuvant chemotherapy treatment [9]. Pathological LN staging is considered the gold standard (GS), based on the evaluation of routine 


\section{Key Points for Decision Makers}

Lymph node (LN) staging is based on conventional goldstandard pathology, which analyses $<1 \%$ of the $\mathrm{LN}$.

LN micrometastases may not be detected by haematoxylin and eosin due to tumour allocation bias, and may cause tumour recurrences.

A more accurate LN staging using the one-step nucleic acid amplification molecular assay could allow a better patient management, and only patients at risk of recurrence would be treated. Savings per patient in unneeded procedures and chemotherapy treatments stretch over the years, and may represent an important economic benefit for the National Health Service.

haemotoxylin and eosin (H\&E)-stained slides; however, evidence indicates that it is not the best methodology of LN staging [10-13]. Significant limitations of this technique are its low sensitivity, since only a small part of the LN is examined [10, 14-18], and the fact that it is a morphologybased analysis [19]. The American Joint Committee on Cancer established that at least $12 \mathrm{LNs}$ should be analysed to assure a reliable pathologic pN0 assessment [20]. Therefore, undetected metastases within the unsampled material may be the cause of an increased risk of local recurrence and/or distant metastases after curative-intent surgery [19]. Yamamoto et al. reported that 6 of 83 OSNA-positive LNs were diagnosed as negative by $\mathrm{H} \& \mathrm{E}$ and immunohistochemical staining (7.2\%) [9]. Other studies report that local recurrence or distant metastases occur in between 10 and 30\% of CRC patients after surgical tumour resection $[6,14,16$, 18]. Moreover, stage II CRC patients with occult LN metastasis are considered a high-risk group for disease recurrence [15], and between 10 and $25 \%$ of these patients die from disease [6, 21]. Therefore, missed LN metastases with the GS method might cause disease understaging, leading to the undertreatment of patients [19].

An innovative technique called one-step nucleic acid amplification assay (OSNA) has been introduced in some hospitals in Europe and within the Asia-Pacific region for detecting LN metastases in patients with breast cancer. OSNA is a quantitative in vitro diagnostic molecular assay system, designed to measure the amount of tumoural cytokeratin 19 (CK19) messenger RNA (mRNA) within LNs $[9,22]$. With OSNA, the LN total tumour burden or total tumour load is defined as the sum of all CK19 mRNA copies present in all dissected LNs of a given case [15, 23]. The total tumour load has already been implemented in routine clinical practice for breast cancer patients, allowing patients to be classified into low- and high-risk groups, independently of the pathologic pN stage and other prognostic factors. In breast cancer, the total tumour load has become a predictive factor for progression. It is related to patient outcome and has become a tool for patient management and decision making [24].

One of the innovative aspects of OSNA is that, unlike the GS technique, OSNA can analyse the whole LN in a short time frame, and in an automatic and standardised way [22]. OSNA is already being used for intraoperative sentinel LN diagnosis in breast carcinoma [23], and has been demonstrated to be a time-efficient tool with standardised assessment of LNs [19]. A CRC meta-analysis including five studies compared the cut-off point of OSNA versus the GS and demonstrated an average sensitivity of $89.4 \%$ and specificity of $93.3 \%$ [19]. In addition, the OSNA assay is faster than the GS technique; OSNA takes 30-40 min to analyse all LNs from two patients, compared with the several hours required for GS analysis [18].

In breast cancer, Saruta and Puig-Junoy estimated savings of US\$346 per patient over a 5-year period when OSNA was used intraoperatively instead of conventional intraoperative sentinel LN biopsy [25]. The National Institute for Health and Care Excellence (NICE) assessed OSNA for CRC staging and estimated an average cost per patient (including capital, maintenance, and disposable costs) of between $£ 568$ and $£ 608$ (excluding value-added tax), depending on the cost of disposables (re-agents and consumables) [22]. Nevertheless, budget impact studies of OSNA for CRC staging are lacking, highlighting the need for economic evaluations assessing OSNA in this patient population. The present study performed a budget impact analysis of OSNA in CRC patients in Spain, comparing two scenarios-GS and OSNA.

\section{Materials and Methods}

\subsection{Perspective and Time Horizon}

A 'what-if' budget impact analysis of introducing OSNA to perform LN analysis in CRC patients in the Spanish National Health System (NHS) was developed using the SensIt program (a sensitivity analysis add-in for Microsoft ${ }^{\circledR}$ Excel 2007-2013 [Microsoft Corporation, Redmond, WA, USA]). The analysis was performed from the NHS perspective. Costs were calculated annually, corresponding to the number of patients newly diagnosed with CRC undergoing surgery during the first year, over a 3-year time horizon from 2017 to 2019. As recommended in budget impact analyses by the International Society for Pharmacoeconomics and Outcomes Research (ISPOR) [26] and by a Spanish pharmacoeconomic guideline [27], costs were not discounted. This analysis follows the ISPOR principles of Good Practice Framework [26]. 


\subsection{Features of the Spanish Health Care System}

The Spanish NHS is a decentralised system covering 17 Spanish regions [28]. Medical procedures, tests and drugs administered in the hospital setting are totally covered by the Spanish health services. In Spain, medical devices are normally acquired by tendering procedures.

\subsection{Eligible Population}

The cohort of patients included in the present analysis comprised Spanish patients diagnosed with CRC who underwent curative-intent surgical excision. Inclusion criteria were patients over 18 years of age with primary histologically confirmed colon carcinoma and positive CK19 immunohistochemistry. Exclusion criteria were based mainly on technical reasons, i.e., open colectomies were excluded due to the risk of CK19 contamination from normal mucosa to LNs that did not contain CK19. Surgical specimens that were fixed in formalin were also excluded since the OSNA assay must be performed on fresh tissue. Rectal tumours treated with neoadjuvant therapy were excluded for the intrinsic difficulty of LN dissection after therapy. Cases with extensive fat infiltration were excluded since LNs cannot be identified and dissected in the middle of primary infiltrating tumour. The analysis was performed based on the estimated patient subgroups according to the recruitment performed by Rakislova et al. regarding systemic therapy (ST) administration [18].

The patient cohort included in the study was obtained from Globocan data (34,331 estimated new cases of CRC in Spain) [29], taking into account that $70.7 \%$ of patients diagnosed with CRC will undergo surgery, as reported by Corral et al. [7]. In our study, the target population was further reduced, and only $74.1 \%$ of surgically treated patients could be included for LN OSNA analysis once the exclusion criteria detailed above were applied. The size of the target population was assumed to be constant over the 3 -year time horizon.

\subsection{Interventions}

Clinical schemes used to populate the model follow CRC National Comprehensive Cancer Network (NCCN) guidelines [20], which are in line with Spanish clinical practice (Fig. 1). The treatment of choice for stage 0 , I, II, or III CRC patients is surgical excision. After surgery, depending on tumour (pT) and LN status (pN) stage, some patients were treated with ST, consisting of different chemotherapy (QT) regimens [30-37]. LN analysis performed using the GS technique implies a risk of misdiagnoses, leading to undertreatment. Undertreated patients may have a higher risk for disease recurrence. According to guidelines, patients showing CRC recurrence might be treated with ST and/or surgery. ST after recurrence consists of QT regimens, which can include biological agents. The OSNA assay detection starts at 250 copies $/ \mu \mathrm{L}$, below 250 copies it is considered negative, allowing the selection of those patients who will very unlikely have tumoural cells in their LNs. However, the OSNA values and the clinical significance do not exactly correlate, and the presence of OSNA positivity does not imply a negative biological effect or patient recurrence by itself. A cut-off of 7500 copies/ $\mu \mathrm{L}$ has been found to be related to a higher risk of recurrence and worse prognosis $[19,38]$. Therefore, the threshold used in this study was 7500 copies/ $\mu \mathrm{L}$; OSNA values $\geq 7500 / \mu \mathrm{L}$ should be considered a positive result.

\subsection{Scenarios and Model Description}

The model compares a reference scenario versus a test scenario over a 3 -year time horizon. The reference scenario assesses the management cost of CRC patients whose LNs have been analysed using the GS technique (H\&E staining), while the test scenario estimates the management cost of CRC patients if LN analysis had been performed using the OSNA technique in the Spanish NHS framework (Fig. 1). Incident patients diagnosed during the first year of the analysis would be followed over the 3-year time horizon in order to collect costs associated with CRC disease.

The proportion of patients with positive or negative LNs, and the proportion of patients receiving ST after a positive or negative LN analysis, differs between scenarios (Fig. 1). In the reference scenario, $78.79 \%$ of patients showed negative LNs using the GS technique [18], of which $15.99 \%$ were treated with ST according to data obtained from three different studies [39-41]. Some negative LN patients were treated based on decisions taken on multidisciplinary committees or recommendations made by clinical guidelines such as the NCCN.

In the reference scenario, $77.32 \%$ of patients with positive LNs by GS received ST $[39,41]$. The model assumes that all patients with negative LNs analysed using the OSNA technique $(86.47 \%$ ) would not receive ST, while $77.32 \%$ of patients with a positive OSNA result (cut-off of $>7500$ copies $/ \mu \mathrm{L} ; 13.53 \%$ ) would be treated with ST. Patients with no ST would enter the follow-up period after surgery, while patients receiving ST would enter the follow-up period after adjuvant treatment. During the first year of followup, $98.10 \%$ and $98.82 \%$ of patients in the reference and test scenarios, underwent and would undergo, respectively, colonoscopies, medical visits, blood tests (including monitoring of carcinoembryonic antigen; CEA) and computed tomography (CT) scans. The proportion of patients using 
Fig. 1 Budget impact scenarios. $C E A$ carcinoembryonic antigen, $C T$ computed tomography, $€$ Euros, GS gold standard, OSNA one-step nucleic acid amplification assay, $S T$ systemic therapy

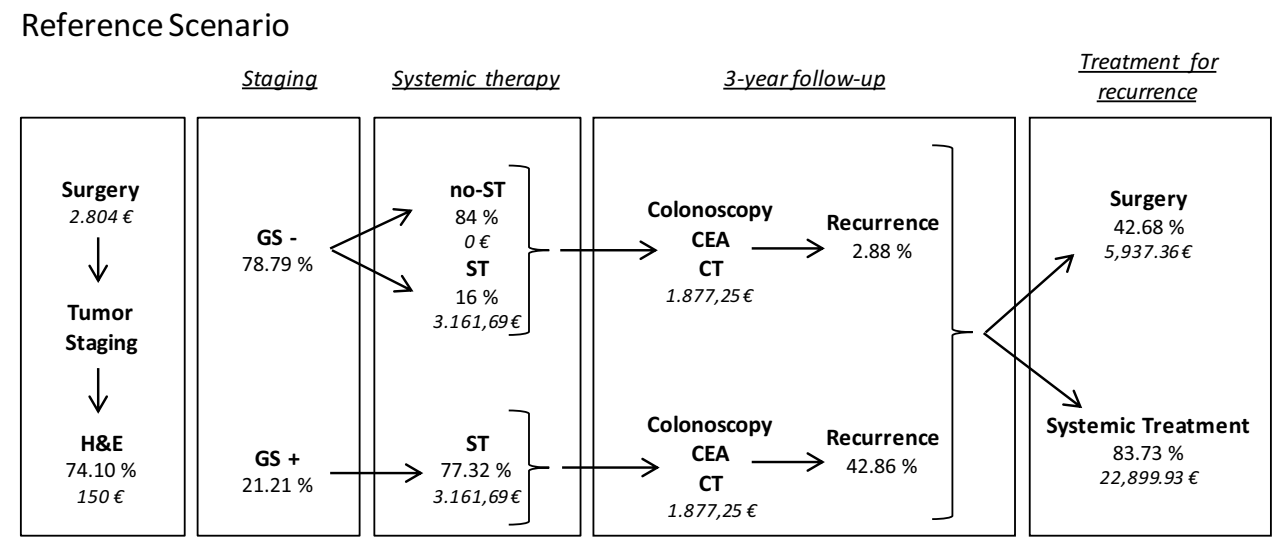

Test Scenario

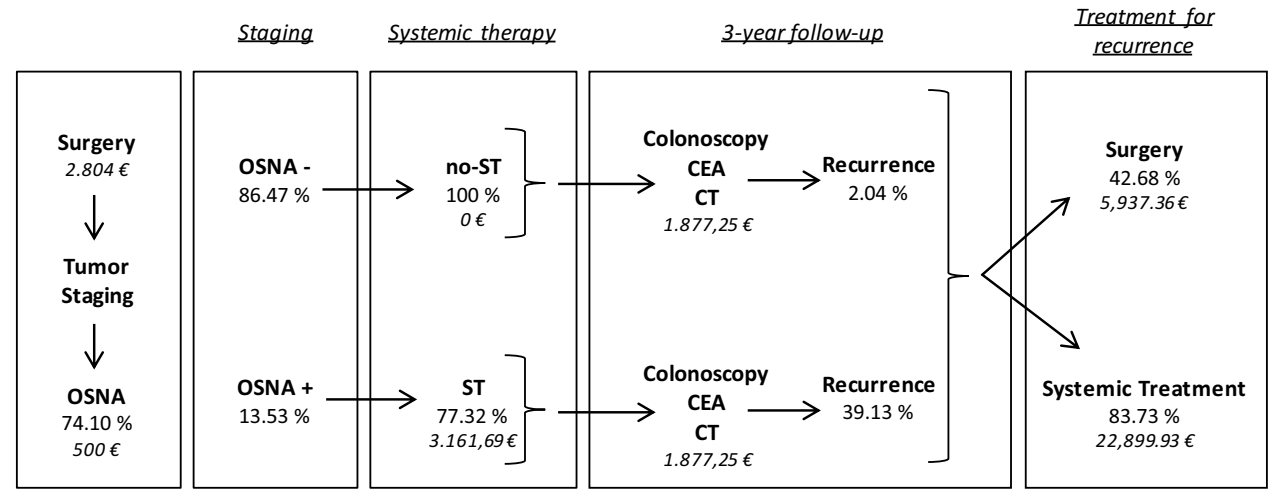

the latter healthcare resources in the reference and test scenarios would be $96.21 \%$ and $97.64 \%$, respectively, during the second year, and $92.42 \%$ and $95.29 \%$, respectively, during the third year. The frequency of tests and visits is described in Table 1.

The percentage of patients with recurrence was obtained from a recently published study comparing GS and OSNA over a 2-year period [18]. Recurrence rates observed by Rakislova et al. [18] during the 2-year period are assumed to be maintained during the third year of the analysis for both the GS and OSNA techniques. In both scenarios, $42.68 \%$ of recurrent patients underwent surgery for recurrence and $83.73 \%$ received ST for recurrence each year of the analysis [40].

\subsection{Input Data}

Assumed parameter values for all clinical and cost data for both scenarios are shown in Table 1, and the strengths, weaknesses and potential data biases are described in electronic supplementary Table $\mathrm{S} 1$. We conducted a search of the Pubmed and eSalud electronic databases using different combinations of keywords, such as 'OSNA', 'colorectal cancer', 'National Health System' and 'costs'. Data credibility was assessed as described in the data extraction protocol (electronic supplementary Table S2).

\subsection{Costs}

The present analysis only includes direct costs from 2017, with all costs given in Euros $(€)$. Drug costs were calculated based on the ex-factory price (PVL, Spanish acronym for Precio de Venta del Laboratorio) [42]. Daily defined doses were obtained from the summary of product characteristics of each drug, and from clinical trials if not specified in the summary of product characteristics. The daily dose per patient was calculated considering an average weight and height of $70.2 \mathrm{~kg}$ and $166 \mathrm{~cm}$, respectively [43]. Regarding drugs administered intravenously, vial wastage was assumed. The cost of ST following first surgery is the average cost of the common QT regimens used in clinical practice, and the cost of ST after recurrence is an average value of the cost of the QT regimens and biological agents (Table 2). An outlier detection technique was used when calculating the average cost of ST, excluding those QT regimens with an annual cost under the average cost divided by two. The cost of other health resources used, such as medical visits and tests, were obtained from the Spanish health costs database [44]. 
Table 1 Inputs used for the base-case and sensitivity analyses

\begin{tabular}{|c|c|c|c|}
\hline Parameters & Inputs & References & Range (lowest-highest) \\
\hline CRC incidence $(N)$ & 34,331 & {$[54]$} & $10-521,490$ \\
\hline Lymph node $(N)$ & 15.00 & {$[55]$} & $10.00-27.00$ \\
\hline GS-negative (\%) & 78.79 & {$[9,18,39]$} & $66.14-100$ \\
\hline GS-positive (\%) & 21.21 & {$[9,16,18]$} & $0.00-33.89$ \\
\hline GS-negative, no ST (\%) & 84.01 & {$[39-41]$} & $79.69-100$ \\
\hline GS-negative, ST (\%) & 15.99 & {$[9,39,40]$} & $12.20-20.30$ \\
\hline GS-positive, ST (\%) & 77.32 & {$[9,39]$} & $62.64-92.00$ \\
\hline OSNA-negative (\%) & 86.47 & {$[16,18]$} & $61.27-100$ \\
\hline OSNA-positive (\%) & 13.53 & {$[16,18]$} & $0.00-33.85$ \\
\hline OSNA-negative, no ST (\%) & 100.00 & {$[20]$} & $79.69-100.00$ \\
\hline OSNA-positive, ST (\%) & 77.32 & {$[39,40]$} & $62.64-92.00$ \\
\hline Recurrence GS-negative (\%) & 1.92 & {$[18,56]$} & $0.00-1.92$ \\
\hline Recurrence GS-positive (\%) & 28.57 & {$[18,56]$} & $0.00-28.57$ \\
\hline ST for recurrence GS (\%) & 83.73 & {$[40]$} & $0.00-100.00$ \\
\hline Surgery for recurrence GS (\%) & 42.68 & [40] & $0.00-100.00$ \\
\hline Recurrence OSNA-negative (\%) & 1.36 & {$[18,56]$} & $0.00-1.36$ \\
\hline Recurrence OSNA-positive (\%) & 26.09 & {$[18,56]$} & $0.00-26.09$ \\
\hline ST for recurrence OSNA (\%) & 83.73 & {$[40]$} & $0.00-100.00$ \\
\hline Surgery for recurrence OSNA (\%) & 42.68 & [40] & $0.00-100.00$ \\
\hline Recurrence GS (\%) ${ }^{\mathrm{a}}$ & 3.79 & {$[18]$} & $0.00-7.58$ \\
\hline Recurrence OSNA $(\%)^{\mathrm{a}}$ & 2.36 & {$[18]$} & $0.00-4.71$ \\
\hline Hospitalisation days $(N)$ & 7.00 & {$[57]$} & $1-14$ \\
\hline Blood test, CEA, visits $(N)$ & 4.00 & {$[20]$} & $2.00-8.00$ \\
\hline Abdominal CT $(N)$ & 1.00 & {$[20]$} & $1.00-3.00$ \\
\hline Thoracoabdominal CT $(N)$ & 1.00 & {$[20]$} & $0.00-2.00$ \\
\hline Colonoscopy $(N)$ & 1.00 & {$[20]$} & $0.00-2.00$ \\
\hline Surgery after diagnosis $(€)$ & 2804.00 & [44] & $1402.00-5608.00$ \\
\hline GS (cost per lymph node; $€$ ) & 10.00 & {$[44]$} & $5.00-20.00$ \\
\hline OSNA (cost per patient; $€$ ) & 500.00 & {$[58]^{\mathrm{b}}$} & $250-700$ \\
\hline Hospitalisation daily cost $(€)$ & 347.00 & {$[44]$} & $112.00-582.00$ \\
\hline ST after first surgery $(€)$ & 2293.66 & {$[20,42,43,56,59-65]$} & $687.91-3739.75$ \\
\hline Colonoscopy $(€)$ & 235.51 & [44] & $120.00-285.00$ \\
\hline CEA $(€)$ & 29.00 & {$[44]$} & $20.00-38.00$ \\
\hline Blood test $(€)$ & 99.19 & {$[44]$} & $46.78-184.89$ \\
\hline Thoracoabdominal $(€)$ & 134.33 & {$[44]$} & $73.00-165.00$ \\
\hline Abdominal CT $(€)$ & 135.00 & [44] & $62.00-168.00$ \\
\hline Medical visit $(€)$ & 26.57 & [44] & $21.60-29.88$ \\
\hline ST after recurrence $(€)$ & $21,966.71$ & {$[20,42,43,59-73]$} & $687.91-32,538.31$ \\
\hline Surgery for recurrence $(€)$ & 5937.00 & {$[44]$} & $5038.00-7252.00$ \\
\hline
\end{tabular}

$C E A$ carcinoembryonic antigen, $C R C$ colorectal cancer, $C T$ computed tomography, $G S$ gold standard, $N$ number of patients, OSNA one-step nucleic acid amplification assay, $S T$ systemic therapy, $€$ Euros

${ }^{a}$ Refers to the overall recurrence rate during the first year in both scenarios, independently of the results obtained

${ }^{\mathrm{b}}$ Data provided by the manufacturer

\subsection{Sensitivity Analyses}

A one-way sensitivity analysis (OWSA) was performed in order to assess the uncertainty and robustness of the model. Clinical and cost parameters were increased and decreased according to the minimum and maximum values shown in Table 1, which were mostly obtained from the literature. For the purposes of sensitivity analyses, the lowest (Vanuatu) and highest (China) number of possible incident patients worldwide was considered [29]. 
In addition, a two-way sensitivity analysis (TWSA) was performed to further assess the uncertainty regarding those clinical parameters that were correlated and should be simultaneously varied; varying them independently may show misleading results: 'positivity of GS vs. OSNA', 'recurrence in follow-up: GS vs. OSNA', 'recurrence in ST: GS vs. OSNA' and 'ST after recurrence with GS vs. OSNA'.

\section{Results}

\subsection{Target Population}

The number of patients diagnosed with CRC who underwent surgery was estimated as 24,265 per year, of which 17,980 would be eligible for OSNA. In the reference scenario, 5214 patients would receive ST after surgery, whereas in the test scenario, only OSNA-positive patients (1615) would receive ST after surgery. More patients in the reference scenario (1362) recurred than in the test scenario (727), and, after recurrence, fewer patients in the test scenario would undergo surgery (310 vs. 581) and receive ST compared with the reference scenario (608 vs. 1140).

\subsection{Budget Impact After the Introduction of the One-Step Nucleic Amplification Technique}

The overall cost of the reference scenario for the first, second and third years was estimated at $€ 182,711,803, € 52,101,734$ and $€ 62,878,813$, respectively, while in the test scenario, the overall cost for the first, second and third years was $€ 181,202,621, € 45,247,233$ and $€ 52,064,732$, respectively. From these results, the corresponding savings were estimated to be $€ 1,509,182$ in year $1, € 6,854,501$ in year 2 , and $€ 10,814,082$ in year 3 , corresponding to savings of $0.002 \%$, $0.010 \%$ and $0.016 \%$ in the Spanish public health expenditure in 2014 (€66,826 million) [45]. Therefore, the introduction of OSNA in Spanish clinical practice for performing LN analysis from CRC surgical specimens could lead to an overall cost saving of $€ 19,177,765$ for the Spanish NHS over a 3-year time horizon (Table 3).

The overall cost per patient using the GS or OSNA techniques is estimated to be $€ 13,193$ and $€ 12,126$, respectively. Therefore, cost savings of $€ 1067$ per patient for the next 3 years after CRC diagnosis are achievable if the OSNA technique replaced the GS technique in the Spanish NHS.

\subsection{Sensitivity Analyses}

Results obtained from the OWSA and TWSA show the robustness of the analysis performed and confirm the results obtained (Figs. 2, 3, respectively). The parameters with a higher impact on the results are those relating to the proportion of patients with negative results, using both the GS and OSNA techniques, and the treatment cost after diagnosis and recurrence. The results obtained by reducing and increasing the parameters included in the analysis are in line with the base-case results, therefore generating savings for the Spanish NHS if OSNA was introduced in clinical practice (Fig. 2). Figure 3 shows that in each of the four analyses, the base case is located within the area under the line, where savings for the NHS would be expected. Lines drawn in Fig. 3 show simultaneous variations of the two parameters included in each analysis.

\section{Discussion}

This study focuses on a novel way of assessing the economic impact of the use of OSNA instead of the traditional GS technique for CRC patients in Spain. Our results indicate that the Spanish NHS would have saved over $€ 19$ million from 2017 to 2019 if OSNA had been introduced in clinical practice for surgically treated CRC patients. Savings are explained by the fact that OSNA ensures a more accurate diagnosis in CRC patients, allowing a reduction in treatment costs after initial surgery, as well as costs of adjuvant treatments and surgery after recurrence, compared with GS techniques. Although patients' LN staging is more expensive with OSNA than with GS, savings regarding treatment costs after surgery and treatment costs due to recurrence are high enough to make a return on the investment made by the incorporation of OSNA at the diagnostic stage. Savings have already been observed during the first year, and increase during the second and third years of the analysis. Sensitivity analyses showed the robustness of the analysis. The number of incident patients is the variable showing a higher impact on the result in the OWSA (the higher the patient population, the greater the savings for the NHS). According to Globocan data [29], the countries reporting the lowest and highest crude incidence rate for CRC are Gambia and Japan, respectively. If these incidence rates were applied to the Spanish population, the number of incidence cases per year would be approximately between 238 and 54,404.

A previous study performed with breast cancer patients in Japan over a 5-year time horizon showed that the use of OSNA would lead to relevant Japanese healthcare savings of approximately US\$121,877,910 [25]. In addition to the difference of diagnosis, treatment and follow-up, the influence of pathological nodal staging on treatment decision in breast cancer and CRC is different. In CRC, the aim is to pursue those cases at risk of recurrence, while in breast carcinoma, a surgical decision of performing lymphadenectomy is undertaken, which does not depend on pathological 
Table 2 Systemic treatments considered following the first surgery and after recurrence

Molecule Dose per cycle No. of cycles Cost per cycle $(€)$ Annual cost $(€)$ per year

ST following first surgery; clinical data sources

Capecitabine [37]

CAPOX $^{\mathrm{a}}[31,35,36]$

CAPOX $^{\mathrm{a}}[31,35,36]$

Fluorouracil/leucovorin (bimonthly) [30, 32-34, 60]

FOLFOX $4^{\mathrm{b}}[30,31,35,36,60]$

FOLFOX $4^{\text {b }}[30,31,35,36,60]$

ST for recurrence; clinical data sources

Bevacizumab/CAPOX [69, 74]

Bevacizumab/FOLFOX6 [69]

Bevacizumab/FOLFIRI [68-70]

Bevacizumab/FOLFOXIRI [68]

Cetuximab/FOLFOX6 [69]

Cetuximab/FOLFOX6 [69]

Cetuximab/FOLFIRI [69]

Cetuximab/FOLFIRI [69]

\begin{tabular}{|c|c|c|c|c|}
\hline Capecitabine & $35,000 \mathrm{mg} / \mathrm{m}^{2}$ & 8 & 116.13 & 929.04 \\
\hline Capecitabine & $28,000 \mathrm{mg} / \mathrm{m}^{2}$ & 4 & 410.80 & 1643.22 \\
\hline Oxaliplatin & $130 \mathrm{mg} / \mathrm{m}^{2}$ & & & \\
\hline Capecitabine & $28,000 \mathrm{mg} / \mathrm{m}^{2}$ & 8 & 410.80 & 3286.43 \\
\hline Oxaliplatin & $130 \mathrm{mg} / \mathrm{m}^{2}$ & & & \\
\hline Fluorouracil & $400 \mathrm{mg} / \mathrm{m}^{2}$ & 12 & 57.33 & 687.91 \\
\hline Fluorouracil & $1200 \mathrm{mg} / \mathrm{m}^{2}$ & & & \\
\hline Leucovorin & $200 \mathrm{mg} / \mathrm{m}^{2}$ & & & \\
\hline Oxaliplatin & $85 \mathrm{mg} / \mathrm{m}^{2}$ & 6 & 311.65 & 1869.87 \\
\hline Leucovorin & $200 \mathrm{mg} / \mathrm{m}^{2}$ & & & \\
\hline Fluorouracil & $400 \mathrm{mg} / \mathrm{m}^{2}$ & & & \\
\hline Fluorouracil & $2400 \mathrm{mg} / \mathrm{m}^{2}$ & & & \\
\hline Oxaliplatin & $85 \mathrm{mg} / \mathrm{m}^{2}$ & 12 & 311.65 & 3739.75 \\
\hline Leucovorin & $200 \mathrm{mg} / \mathrm{m}^{2}$ & & & \\
\hline Fluorouracil & $400 \mathrm{mg} / \mathrm{m}^{2}$ & & & \\
\hline Fluorouracil & $2400 \mathrm{mg} / \mathrm{m}^{2}$ & & & \\
\hline Bevacizumab & $7.5 \mathrm{mg} / \mathrm{kg}$ & 12 & 1733.60 & $20,803.25$ \\
\hline CAPOX & a & & & \\
\hline Bevacizumab & $5 \mathrm{mg} / \mathrm{kg}$ & 12 & 1634.45 & $19,613.35$ \\
\hline FOLFOX6 & $\mathrm{b}$ & & & \\
\hline Bevacizumab & $5 \mathrm{mg} / \mathrm{kg}$ & 12 & 1453.40 & $17,440.75$ \\
\hline Irinotecan & $360 \mathrm{mg} / \mathrm{m}^{2}$ & & & \\
\hline Leucovorin & $800 \mathrm{mg} / \mathrm{m}^{2}$ & & & \\
\hline Fluorouracil & $400 \mathrm{mg} / \mathrm{m}^{2}$ & & & \\
\hline Fluorouracil & $4800 \mathrm{mg} / \mathrm{m}^{2}$ & & & \\
\hline Bevacizumab & $5 \mathrm{mg} / \mathrm{kg}$ & 12 & 1682.02 & $20,184.27$ \\
\hline Irinotecan & $165 \mathrm{mg} / \mathrm{m}^{2}$ & & & \\
\hline Oxaliplatin & $85 \mathrm{mg} / \mathrm{m}^{2}$ & & & \\
\hline Leucovorin & $200 \mathrm{mg} / \mathrm{m}^{2}$ & & & \\
\hline Fluorouracil & $3200 \mathrm{mg} / \mathrm{m}^{2}$ & & & \\
\hline Cetuximab & $500 \mathrm{mg} / \mathrm{m}^{2}$ & 12 & 2111.56 & $25,338.67$ \\
\hline FOLFOX6 & $\mathrm{b}$ & & & \\
\hline Cetuximab & $650 \mathrm{mg} / \mathrm{m}^{2}$ & 12 & 2711.53 & $32,538.31$ \\
\hline FOLFOX6 & $\mathrm{b}$ & & & \\
\hline Cetuximab & $500 \mathrm{mg} / \mathrm{kg}$ & 12 & 1930.51 & $23,166.07$ \\
\hline Irinotecan & $180 \mathrm{mg} / \mathrm{m}^{2}$ & & & \\
\hline Leucovorin & $400 \mathrm{mg} / \mathrm{m}^{2}$ & & & \\
\hline Fluorouracil & $400 \mathrm{mg} / \mathrm{m}^{2}$ & & & \\
\hline Fluorouracil & $2400 \mathrm{mg} / \mathrm{m}^{2}$ & & & \\
\hline Cetuximab & $400 \mathrm{mg} / \mathrm{m}^{2}$ & 12 & 2530.51 & $30,365.71$ \\
\hline Irinotecan & $180 \mathrm{mg} / \mathrm{m}^{2}$ & & & \\
\hline Leucovorin & $400 \mathrm{mg} / \mathrm{m}^{2}$ & & & \\
\hline Fluorouracil & $400 \mathrm{mg} / \mathrm{m}^{2}$ & & & \\
\hline Fluorouracil & $2400 \mathrm{mg} / \mathrm{m}^{2}$ & & & \\
\hline
\end{tabular}


Table 2 (continued)

\begin{tabular}{lllll}
\hline & Molecule & Dose per cycle & $\begin{array}{l}\text { No. of cycles } \\
\text { per year }\end{array}$ & Cost per cycle $(€)$ Annual cost $(€)$ \\
\hline Panitumumab/FOLFIRI [75] & Panitumumab & $6 \mathrm{mg} / \mathrm{kg}$ & 12 & 1958.95 \\
& Irinotecan & $180 \mathrm{mg} / \mathrm{m}^{2}$ & & $23,507.35$ \\
& Leucovorin & $400 \mathrm{mg} / \mathrm{m}^{2}$ & & \\
& Fluorouracil & $400 \mathrm{mg} / \mathrm{m}^{2}$ & & 2140.00 \\
& Fluorouracil & $2400 \mathrm{mg} / \mathrm{m}^{2}$ & & $25,679.95$ \\
Panitumumab/FOLFOX6 [72] & Panitumumab & $6 \mathrm{mg} / \mathrm{kg}$ & 12 & \\
\hline
\end{tabular}

$S T$ systemic therapy, $€$ Euros

${ }^{a}$ Treatment regimen includes the same molecules and doses per cycle indicated for CAPOX

${ }^{\mathrm{b}}$ Treatment regimen includes the same molecules and doses per cycle indicated for FOLFOX4

Table 3 Results of the budget impact of introducing OSNA in Spanish clinical practice over a 3-year time horizon (Euros)

\begin{tabular}{|c|c|c|c|c|c|c|}
\hline & \multicolumn{2}{|l|}{ Year 1} & \multicolumn{2}{|l|}{ Year 2} & \multicolumn{2}{|l|}{ Year 3} \\
\hline & $\begin{array}{l}\text { Reference scenario } \\
\text { (GS) }\end{array}$ & $\begin{array}{l}\text { Test scenario } \\
\text { (OSNA) }\end{array}$ & $\begin{array}{l}\text { Reference } \\
\text { scenario(GS) }\end{array}$ & $\begin{array}{l}\text { Test scenario } \\
\text { (OSNA) }\end{array}$ & $\begin{array}{l}\text { Reference scenario } \\
\text { (GS) }\end{array}$ & $\begin{array}{l}\text { Test scenario } \\
\text { (OSNA) }\end{array}$ \\
\hline Surgery & $126,983,355$ & $126,983,355$ & 0.00 & 0.00 & 0.00 & 0.00 \\
\hline Staging & $2,697,072$ & $8,990,240$ & 0.00 & 0.00 & 0.00 & 0.00 \\
\hline ST after first surgery & $11,959,135$ & $4,314,396$ & 0.00 & 0.00 & 0.00 & 0.00 \\
\hline Follow-up & $33,114,221$ & $33,355,561$ & $31,856,889$ & $32,565,720$ & $30,628,249$ & $31,789,382$ \\
\hline Recurrence surgery & $1,691,066$ & $1,606,289$ & $1,658,940$ & $1,040,519$ & $1,626,814$ & $1,028,025$ \\
\hline ST after recurrence & $6,266,955$ & $5,952,781$ & $18,585,905$ & $11,640,994$ & $30,623,750$ & $19,247,325$ \\
\hline Total cost & $182,711,803$ & $181,202,621$ & $52,101,734$ & $45,247,233$ & $62,878,813$ & $52,064,732$ \\
\hline Budget impact & $1,509,182$ & & $6,854,501$ & & $10,814,082$ & \\
\hline
\end{tabular}

GS gold standard, OSNA one-step nucleic acid amplification assay, $S T$ systemic therapy

nodal staging. Therefore, these results do not directly relate/ correspond to those obtained in the present study.

Several authors agree on using more sensitive molecular methods of LN staging in CRC, rather than GS [11, 12, 46-49], to help identify CRC patients who are histologically LN-negative after a potentially curative surgical resection and who are nevertheless at risk of recurrence [12, 47, 48]. Precise pathological LN staging is critical in determining the most suitable treatment $[50,51]$. Nevertheless, not only are new techniques needed to achieve better patient staging but also new treatments with improved outcomes, as efficacy observed with current chemotherapy regimens for CRC is limited [52].

The results of the present study relate to Spain, however the OSNA technique could also be incorporated in other countries. Further studies comparing clinical outcomes such as recurrence rates or overall survival between patients whose LNs have been analysed using the OSNA technique versus the GS technique would be of interest. Moreover, although this study reports a relevant economic benefit for the Spanish NHS in a scenario using OSNA, further pharmacoeconomic evaluations, such as cost-effectiveness analysis, could also help health services make informed decisions regarding the feasibility of introducing OSNA in their clinical practice.

\subsection{Limitations}

Pharmacoeconomic studies are subject to limitations, mainly due to the fact that reality ought to be simplified in order to elaborate the model. The present analysis assumed that the size of the target population remained unchanged over the 3 -year period in order to collect all costs associated with the incident cohort. At the time of the study, no data were available regarding the mortality rates compared between OSNA and GS. Furthermore, clinical data used to calculate the proportion of patients with negative and positive results in the reference and test scenarios were taken from different studies including a sample of patients, which might differ from real clinical practice in Spain. However, inputs regarding the staging and recurrence rates of patients were obtained from the same study for consistency. Additionally, the proportion 


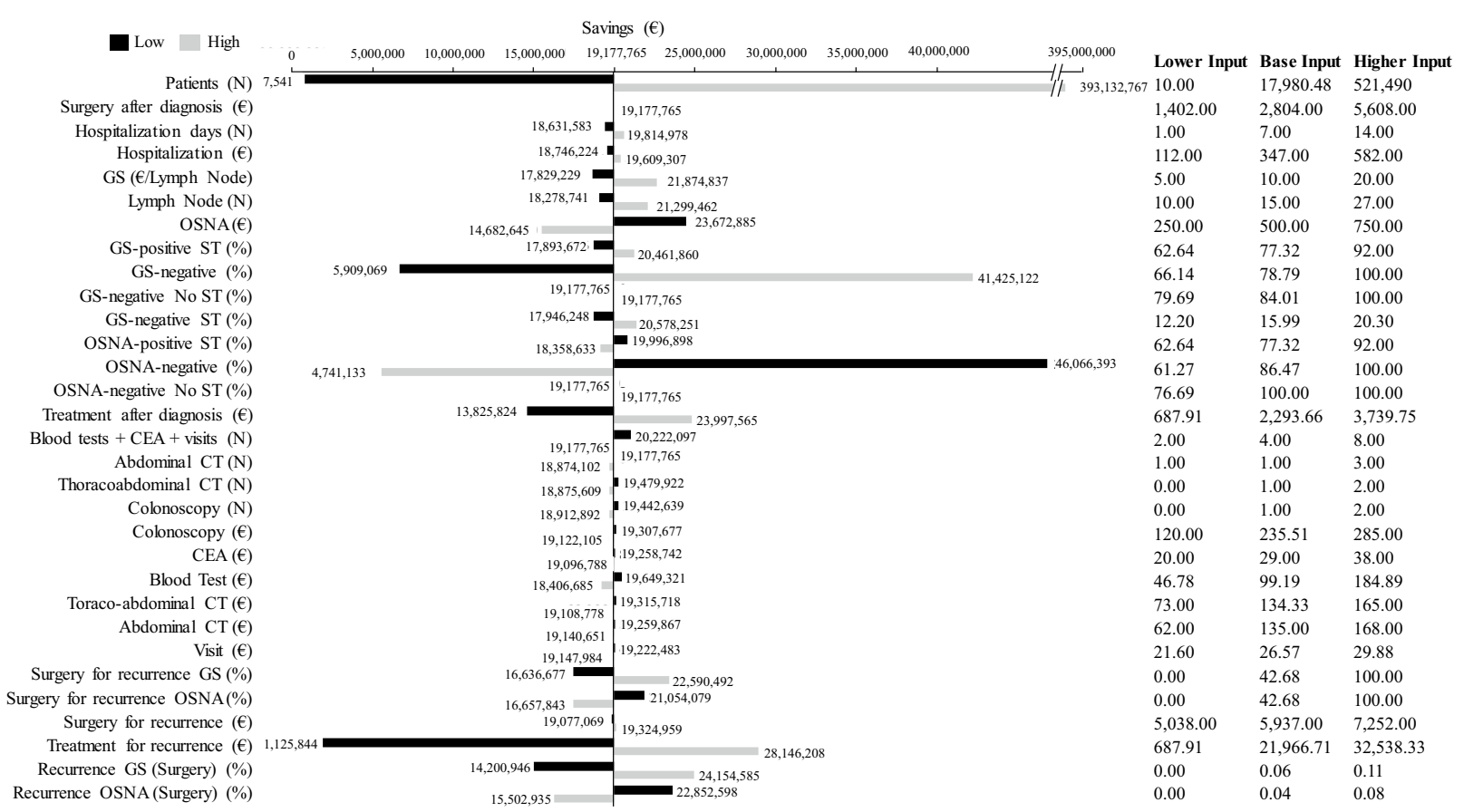

Fig. 2 Tornado diagram, one-way sensitivity analysis results. Vertical line indicates the total cost saving from the base case, and the horizontal lines indicate the shift in the range of outputs obtained by varying each input to a lower (black) and higher (light grey) value.

of negative and positive OSNA results might be associated with sample bias in the study design, which was performed according to the actual guidelines of $\mathrm{LN}$ analysis and staging in CRC. To date, all CRC studies performed using OSNA have the same sample bias, resulting from using part of the LNs for H\&E analysis and GS staging, and using the rest for OSNA. Consequently, metastasis might have only been present in part of the $\mathrm{H} \& \mathrm{E}$ analysis, leading to false negative OSNA results $[17,18,53]$.

Furthermore, another limitation is in regard to data obtained from Rakislova et al. [18], as LNs were analysed using both the GS and OSNA techniques, and treated according to the GS diagnosis. Therefore, patient outcomes remain unknown in the hypothetical case that patients' treatment decisions would have only been based on the OSNA results. Hence, a randomised study is needed to obtain accurate outcomes in those patients treated after the OSNA results had been reported and those treated after GS diagnosis, in order to assess a possible differential treatment effect depending on the staging diagnostic procedure performed, i.e., OSNA or GS. Costs related to adverse effects and adverse events management were not included in both interventions since
$C E A$ carcinoembryonic antigen, $C T$ computed tomography, $G S$ gold standard, $N$ number of patients, OSNA one-step nucleic acid amplification assay, $S T$ systemic therapy, $\ell$ Euros

they are the same for both OSNA and GS. Diagnosis is performed after tissue containing the tumour is resected from the patient. Therefore, patients do not undergo extra interventions as $\mathrm{LN}$ analysis is performed in the laboratory, with no adverse events for the patient. Thus, adverse events relating to diagnostic techniques for CRC have not been identified.

\section{Conclusions}

The introduction of OSNA for the management of CRC patients in Spanish clinical practice may represent an economic benefit for the NHS, as well as clinical benefit for CRC patients. OSNA results offer higher diagnostic reliability than the currently used GS techniques. The introduction of OSNA may allow more accurate staging of patients, which could help in avoiding unnecessary treatments without affecting a patient's prognosis (recurrence), or may provide the opportunity to receive treatment for those patients who could really benefit from it. 


\section{Recurrence GS vs OSNA in Follow-up}

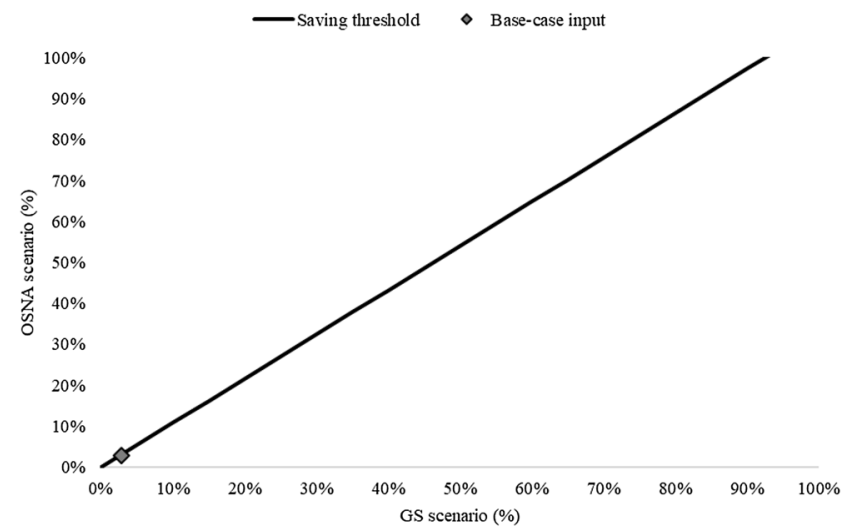

ST after Recurrence

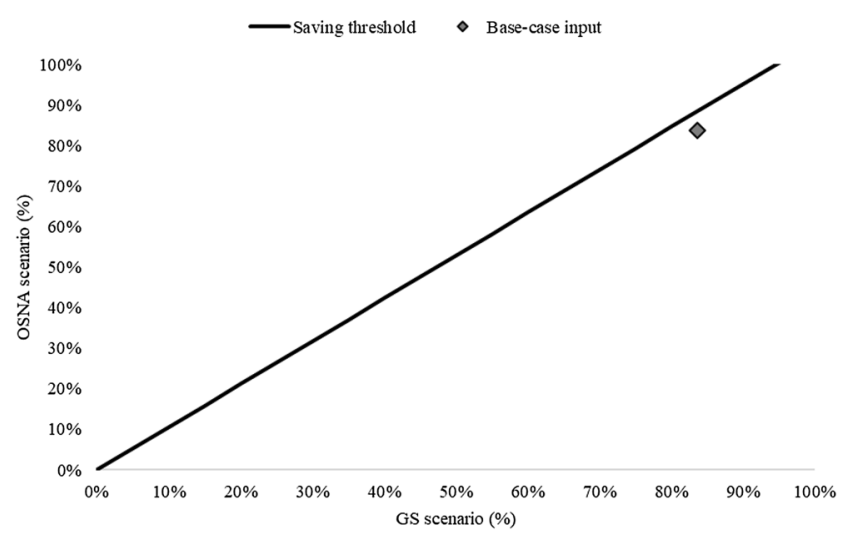

Positivity GS vs OSNA

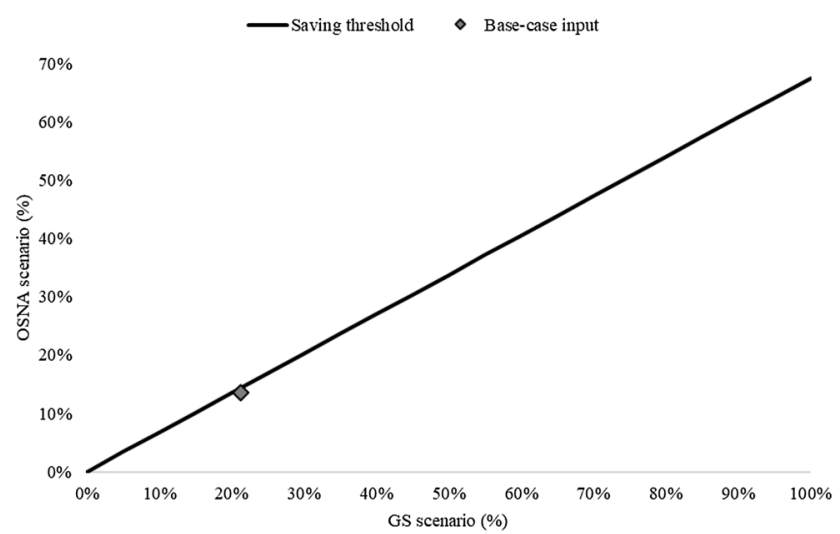

Recurrence GS vs OSNA in ST

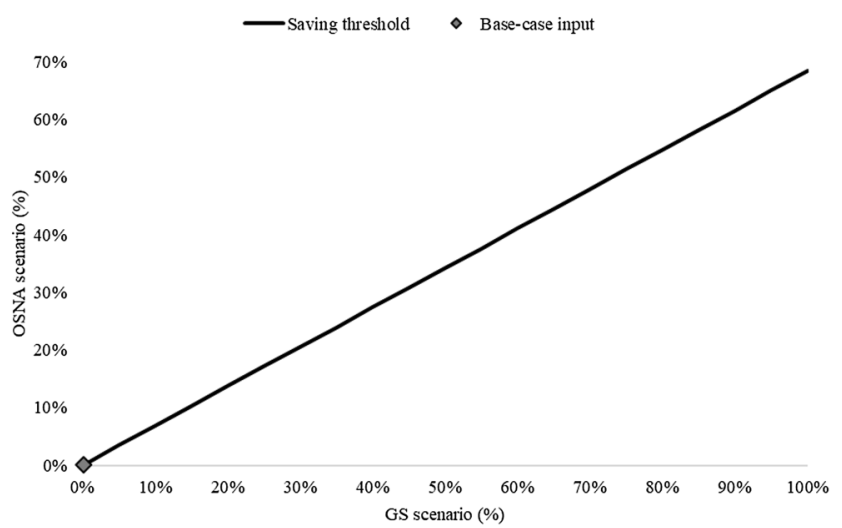

Fig. 3 Two-way sensitivity analysis results. GS gold standard, OSNA one-step nucleic acid amplification assay, ST systemic therapy

Acknowledgements The authors acknowledge Clara Carrascosa for her technical support, and Sysmex Coorp Spain (Sant Just Desvern, Spain) for the technical advice and support provided.

\section{Compliance with Ethical Standards}

Funding This work was supported by Grants from the Instituto de Salud Carlos III (PI17/01304), Fundación Científica de la Asociación Española Contra el Cáncer (GCB13131592CAST), Ministerio de Economía y Competitividad (SAF2014-54453-R), and Agència de Gestió d'Ajuts Universitaris i de Recerca (2017SGR653 and 2017SGR00735), as well as by the Banc de Tumors-Biobanc Hospital Clinic-IDIBAPS and Xarxa de Bancs de Tumors de Catalunya (XBTC). CIBERehd is funded by the Instituto de Salud Carlos III. The authors also acknowledge the support of the CERCA Programme/Generalitat de Catalunya.

Author contributions MC, IAr, JMB, SD-M, IAl, and AC contributed to the conception and planning of the work that led to the manuscript; acquisition, analysis and interpretation of the data; drafting and/or critical revision of the manuscript for important intellectual content; and approval of the final version of the submitted manuscript. AI, AdL, $\mathrm{DM}, \mathrm{FB}, \mathrm{IG}, \mathrm{JAB}, \mathrm{JC}, \mathrm{JM}$, and $\mathrm{NC}$ contributed to the acquisition, analysis and interpretation of the data, and approval of the final version of the submitted manuscript.
Data availability statement Data are available from the authors upon reasonable request.

Conflict of interest Sherley Diaz-Mercedes, Ivan Archilla, Jordi Camps, Antonio de Lacy, Iñigo Gorostiaga, Dulce Momblan, Ainitze Ibarzabal, Joan Maurel, Nuria Chic, Josep Antoni Bombí, Francesc Balaguer, Antoni Castells, Iban Aldecoa, Josep Maria Borras and Miriam Cuatrecasas declare no conflicts of interest.

Open Access This article is distributed under the terms of the Creative Commons Attribution-NonCommercial 4.0 International License (http://creativecommons.org/licenses/by-nc/4.0/), which permits any noncommercial use, distribution, and reproduction in any medium, provided you give appropriate credit to the original author(s) and the source, provide a link to the Creative Commons license, and indicate if changes were made.

\section{References}

1. Bray F, Ferlay J, Soerjomataram I, Siegel RL, Torre LA, Jemal A. Global cancer statistics 2018: GLOBOCAN estimates of incidence and mortality worldwide for 36 cancers in 185 countries. CA Cancer J Clin. 2018;68(6):394-424. 
2. Sociedad Española de Oncología Médica (SEOM). Las Cifras del Cáncer en España. 2018.

3. Globocan, International Agency for Research on Cancer. World Cancer Fact Sheet. GLOBOCAN. 2013 ed. Lyon: International Agency for Research on Cancer. http://globocan.iarc.fr/Pages/ fact_sheets_cancer.aspx. Accessed 6 Sept 2018.

4. Office for National Statistics. Cancer survival in England-adults diagnosed: 2008-2012, followed up to 2013 London: Office for National Statistics; 2014.

5. Rachet B, Maringe C, Nur U, Quaresma M, Shah A, Woods LM, et al. Population-based cancer survival trends in England and Wales up to 2007: an assessment of the NHS cancer plan for England. Lancet Oncol. 2009;10(4):351-69.

6. Pahlman LA, Hohenberger WM, Matzel K, Sugihara K, Quirke $\mathrm{P}$, Glimelius B. Should the benefit of adjuvant chemotherapy in colon cancer be re-evaluated? J Clin Oncol. 2016;34(12):1297-9.

7. Corral J, Castells X, Molins E, Chiarello P, Borras JM, Cots F. Long-term costs of colorectal cancer treatment in Spain. BMC Health Serv Res. 2016;16:56.

8. Valentini V, Aristei C, Glimelius B, Minsky BD, Beets-Tan R, Borras JM, et al. Multidisciplinary rectal cancer management: 2nd European rectal cancer consensus conference (EURECA-CC2). Radiother Oncol. 2009;92(2):148-63.

9. Compton CC. Optimal pathologic staging: defining stage II disease. Clin Cancer Res. 2007;13(22):6862s-70s.

10. Yamamoto H, Sekimoto M, Oya M, Yamamoto N, Konishi F, Sasaki J, et al. OSNA-based novel molecular testing for lymph node metastases in colorectal cancer patients: results from a multicenter clinical performance study in Japan. Ann Surg Oncol. 2011;18(7):1891-8.

11. Hyslop T, Waldman SA. Molecular staging of node negative patients with colorectal cancer. J Cancer. 2013;4(3):193.

12. Rahbari NN, Bork U, Motschall E, Thorlund K, Büchler MW, Koch M, et al. Molecular detection of tumor cells in regional lymph nodes is associated with disease recurrence and poor survival in node-negative colorectal cancer: a systematic review and meta-analysis. J Clin Oncol. 2011;30(1):60-70.

13. Weitz J, Kienle P, Magener A, Koch M, Schrödel A, Willeke $F$, et al. Detection of disseminated colorectal cancer cells in lymph nodes, blood and bone marrow. Clin Cancer Res. 1999;5(7):1830-6.

14. Croner RS, Geppert CI, Bader FG, Nitsche U, Spath C, Rosenberg R, et al. Molecular staging of lymph node-negative colon carcinomas by one-step nucleic acid amplification (OSNA) results in upstaging of a quarter of patients in a prospective, European, multicentre study. Br J Cancer. 2014;110(10):2544-50.

15. Yamamoto H, Tomita N, Inomata M, Furuhata $\mathrm{T}$, Miyake $\mathrm{Y}$, Noura S, et al. OSNA-assisted molecular staging in colorectal cancer: a prospective multicenter trial in Japan. Ann Surg Oncol. 2016;23(2):391-6.

16. Vogelaar FJ, Reimers MS, van der Linden RL, van der Linden JC, Smit VT, Lips DJ, et al. The diagnostic value of one-step nucleic acid amplification (OSNA) for sentinel lymph nodes in colon cancer patients. Ann Surg Oncol. 2014;21(12):3924-30.

17. Aldecoa I, Atares B, Tarragona J, Bernet L, Sardon JD, Pereda $\mathrm{T}$, et al. Molecularly determined total tumour load in lymph nodes of stage I-II colon cancer patients correlates with highrisk factors. A multicentre prospective study. Virchows Arch. 2016;469(4):385-94.

18. Rakislova N, Montironi C, Aldecoa I, Fernandez E, Bombi JA, Jimeno M, et al. Lymph node pooling: a feasible and efficient method of lymph node molecular staging in colorectal carcinoma. J Transl Med. 2017;15(1):14.

19. Wild JB, Iqbal N, Francombe J, Papettas T, Sanders DS, Ramcharan S. Is it time for one-step nucleic acid amplification (OSNA) in colorectal cancer? A systematic review and meta-analysis. Tech Coloproctol. 2017;21(9):693-9.

20. National Comprehensive Cancer Network. NCCN Guidelines for Patients: Colon Cancer. National Comprehensive Cancer Network; 2016, 2017. Available at: https://www.ncen.org.

21. Weitz J, Koch M, Debus J, Hohler T, Galle PR, Buchler MW. Colorectal cancer. Lancet. 2005;365(9454):153-65.

22. National Institute for Health and Care Excellence (NICE). OSNA for colon cancer staging. 2016. https://www.nice.org.uk/advice/ mib77/resources/osna-for-colon-cancer-staging-pdf-6349935249 8629. Accessed 24 July 2018.

23. Peg V, Espinosa-Bravo M, Vieites B, Vilardell F, Antunez JR, de Salas MS, et al. Intraoperative molecular analysis of total tumor load in sentinel lymph node: a new predictor of axillary status in early breast cancer patients. Breast Cancer Res Treat. 2013;139(1):87-93.

24. Peg V, Sansano I, Vieites B, Bernet L, Cano R, Córdoba A, et al. Role of total tumour load of sentinel lymph node on survival in early breast cancer patients. Breast. 2017;33:8-13.

25. Saruta Y, Puig-Junoy J. Cost and budget impact analysis of an accurate intraoperative sentinel lymph node diagnosis for breast cancer metastasis. Appl Health Econ Health Policy. 2016;14(3):323-35.

26. Sullivan SD, Mauskopf JA, Augustovski F, Jaime Caro J, Lee KM, Minchin M, et al. Budget impact analysis-principles of good practice: report of the ISPOR 2012 Budget Impact Analysis Good Practice II Task Force. Value Health. 2014;17(1):5-14.

27. Puig-Junoy J, Oliva-Moreno J, Trapero-Bertran M. AbellánPerpiñán JM, Brosa-Riestra M, Servei Català de la Salut (CatSalut). Guia i recomanacions per a la realització i presentació $\mathrm{d}$ 'avaluacions econòmiques i anàlisis d'impacte pressupostari de medicaments en l'àmbit del CatSalut. Barcelona: Generalitat de Catalunya. Departament de Salut. Servei Català de la Salut; 2014.

28. MSSSI. Ministerio de Sanidad Servicios Sociales e Igualdad. Informe Anual del Sistema Nacional de Salud. 2017. https://www. mscbs.gob.es/estadEstudios/estadisticas/sisInfSanSNS/tablasEsta disticas/InfAnSNS.htm. Accessed 25 July 2018.

29. GLOBOCAN. Estimated cancer incidence, mortality and prevalence worldwide in 2012. http://globocan.iarc.fr/Default.aspx. Accessed 23 July 2018.

30. André T, De Gramont A, Vernerey D, Chibaudel B, Bonnetain F, Tijeras-Raballand A, et al. Adjuvant fluorouracil, leucovorin, and oxaliplatin in stage II to III colon cancer: updated 10-year survival and outcomes according to BRAF mutation and mismatch repair status of the MOSAIC study. J Clin Oncol. 2015;33(35):4176-87.

31. Grothey A, Sobrero AF, Shields AF, Yoshino T, Paul J, Taieb $\mathrm{J}$, et al. Duration of adjuvant chemotherapy for stage III colon cancer. N Engl J Med. 2018;378(13):1177-88.

32. Group QC. Adjuvant chemotherapy versus observation in patients with colorectal cancer: a randomised study. Lancet. 2007;370(9604):2020-9.

33. Haller DG, Tabernero J, Maroun J, de Braud F, Price T, Van Cutsem E, et al. Capecitabine plus oxaliplatin compared with fluorouracil and folinic acid as adjuvant therapy for stage III colon cancer. J Clin Oncol. 2011;29(11):1465-71.

34. Kuebler JP, Wieand HS, O'Connell MJ, Smith RE, Colangelo LH, Yothers G, et al. Oxaliplatin combined with weekly bolus fluorouracil and leucovorin as surgical adjuvant chemotherapy for stage II and III colon cancer: results from NSABP C-07. J Clin Oncol. 2007;25(16):2198-204.

35. Shah MA, Renfro LA, Allegra CJ, André T, De Gramont A, Schmoll H-J, et al. Impact of patient factors on recurrence risk and time dependency of oxaliplatin benefit in patients with colon cancer: analysis from modern-era adjuvant studies in the adjuvant colon cancer end points (ACCENT) database. J Clin Oncol. 2016;34(8):843. 
36. Tournigand C, André T, Bonnetain F, Chibaudel B, Lledo G, Hickish T, et al. Adjuvant therapy with fluorouracil and oxaliplatin in stage II and elderly patients (between ages 70 and 75 years) with colon cancer: subgroup analyses of the multicenter international study of oxaliplatin, fluorouracil, and leucovorin in the adjuvant treatment of colon cancer trial. J Clin Oncol. 2012;30(27):3353-60.

37. Twelves C, Wong A, Nowacki MP, Abt M, Burris H III, Carrato A, et al. Capecitabine as adjuvant treatment for stage III colon cancer. N Engl J Med. 2005;352(26):2696-704.

38. Cuatrecasas M. Budget impact of molecular lymph node staging in colorectal carcinoma. Should we invest more in diagnosis? 30th European Congress of Pathology. Virchows Arch. 2018;473(Suppl 1):S1-340.

39. Bilchik A, Nissan A, Wainberg Z, Shen P, McCarter M, Protic $M$, et al. Surgical quality and nodal ultrastaging is associated with long-term disease-free survival in early colorectal cancer: an analysis of 2 international multicenter prospective trials. Ann Surg. 2010;252(3):467-74 (discussion 74-76).

40. Corral J, Borràs JM, Chiarello $\mathrm{P}$, García-Alzorriz E, Macià F, Reig A, et al. Estimación del coste hospitalario del cáncer colorrectal en Cataluña. Gaceta Sanitaria. 2015;29(6):437-44.

41. Weixler B, Warschkow R, Guller U, Zettl A, von Holzen U, Schmied BM, et al. Isolated tumor cells in stage I \& II colon cancer patients are associated with significantly worse disease-free and overall survival. BMC Cancer. 2016;16:106.

42. Consejo General de Colegios Oficiales de Farmacéuticos. Botplus portalfarma. https://botplusweb.portalfarma.com/. Accessed 13 July 2017.

43. Instituto Nacional de Estadística (INE). http://www.ine.es/. Accessed 13 July 2017.

44. Oblikue Consulting S.L. Base de datos de costes sanitarios y ratios coste-efectividad españoles: eSalud. 2018. http://www.oblik ue.com/bddcostes/. Accessed 3 Sept 2018.

45. MSSSI. Ministerio de Sanidad Servicios Sociales e Igualdad. Gasto Sanitario. Informe Anual del Sistema Nacional de Salud. 2016. https://www.mscbs.gob.es/estadEstudios/estadisticas/sisIn fSanSNS/tablasEstadisticas/InfAnualSNS2016/7Gast_Sanit.pdf. Accessed 3 Sept 2018.

46. Sirop S, Kanaan M, Korant A, Wiese D, Eilender D, Nagpal S, et al. Detection and prognostic impact of micrometastasis in colorectal cancer. J Surg Oncol. 2011;103(6):534-7.

47. Sloothaak D, Sahami S, van der Zaag-Loonen HV, Van der Zaag $\mathrm{E}$, Tanis $\mathrm{P}$, Bemelman $\mathrm{W}$, et al. The prognostic value of micrometastases and isolated tumour cells in histologically negative lymph nodes of patients with colorectal cancer: a systematic review and meta-analysis. Eur J Surg Oncol. 2014;40(3):263-9.

48. Iddings D, Ahmad A, Elashoff D, Bilchik A. The prognostic effect of micrometastases in previously staged lymph node negative (N0) colorectal carcinoma: a meta-analysis. Ann Surg Oncol. 2006;13(11):1386-92.

49. Nicastri DG, Doucette JT, Godfrey TE, Hughes SJ. Is occult lymph node disease in colorectal cancer patients clinically significant?: a review of the relevant literature. J Mol Diagn. 2007;9(5):563-71.

50. Schmoll H, Van Cutsem E, Stein A, Valentini V, Glimelius B, Haustermans K, et al. ESMO Consensus Guidelines for management of patients with colon and rectal cancer: a personalized approach to clinical decision making. Ann Oncol. 2012;23(10):2479-516.

51. Van Cutsem E, Borràs JM, Castells A, Ciardiello F, Ducreux M, Haq A, et al. Improving outcomes in colorectal cancer: where do we go from here? Eur J Cancer. 2013;49(11):2476-85.

52. Sociedad Española de Oncología Médica. Información sobre el cáncer. Cáncer de colon y recto. https://www.seom.org/es/ info-sobre-el-cancer/colon-recto?start=8\#content. Accessed 13 July 2018.

53. Aldecoa I, Montironi C, Planell N, Pellise M, Fernandez-Esparrach G, Gines A, et al. Endoscopic tattooing of early colon carcinoma enhances detection of lymph nodes most prone to harbor tumor burden. Surg Endosc. 2017;31(2):723-33.

54. Galceran J, Ameijide A, Carulla M, Mateos A, Quirós J, Rojas D, et al. Cancer incidence in Spain, 2015. Clin Transl Oncol. 2017;19(7):799-825.

55. Li Destri G, Di Carlo I, Scilletta R, Scilletta B, Puleo S. Colorectal cancer and lymph nodes: the obsession with the number 12 . World J Gastroenterol. 2014;20(8):1951-60.

56. Sargent D, Sobrero A, Grothey A, O'Connell MJ, Buyse M, Andre T, et al. Evidence for cure by adjuvant therapy in colon cancer: observations based on individual patient data from 20,898 patients on 18 randomized trials. J Clin Oncol. 2009;27(6):872-7.

57. MSSSI. Ministerio de Sanidad Servicios Sociales e Igualdad. La hospitalización en el Sistema Nacional de Salud CMBD-Registro de altas. Informe resumen 2010. Información y Estadísticas Sanitarias. 2012. https://www.mscbs.gob.es/estadEstudios/estad isticas/docs/Hospitalizacion_SNS_CMBD_Informe2010.pdf. Accessed 13 July 2017.

58. Sysmex Spain. 2018. https://www.sysmex.es/. Accessed 3 Sept 2018.

59. Andre T, Louvet C, Maindrault-Goebel F, Couteau C, Mabro M, Lotz JP, et al. CPT-11 (irinotecan) addition to bimonthly, highdose leucovorin and bolus and continuous-infusion 5-fluorouracil (FOLFIRI) for pretreated metastatic colorectal cancer. GERCOR. Eur J Cancer. 1999;35(9):1343-7.

60. de Gramont A, Figer A, Seymour M, Homerin M, Hmissi A, Cassidy J, et al. Leucovorin and fluorouracil with or without oxaliplatin as first-line treatment in advanced colorectal cancer. J Clin Oncol. 2000;18(16):2938-47.

61. Jager E, Heike M, Bernhard H, Klein O, Bernhard G, Lautz D, et al. Weekly high-dose leucovorin versus low-dose leucovorin combined with fluorouracil in advanced colorectal cancer: results of a randomized multicenter trial. Study Group for Palliative Treatment of Metastatic Colorectal Cancer Study Protocol 1. J Clin Oncol. 1996;14(8):2274-9.

62. Maindrault-Goebel F, de Gramont A, Louvet C, Andre T, Carola E, Gilles V, et al. Evaluation of oxaliplatin dose intensity in bimonthly leucovorin and 48-hour 5-fluorouracil continuous infusion regimens (FOLFOX) in pretreated metastatic colorectal cancer. Oncology Multidisciplinary Research Group (GERCOR). Ann Oncol. 2000;11(11):1477-83.

63. Van Cutsem E, Twelves C, Cassidy J, Allman D, Bajetta E, Boyer M, et al. Oral capecitabine compared with intravenous fluorouracil plus leucovorin in patients with metastatic colorectal cancer: results of a large phase III study. J Clin Oncol. 2001;19(21):4097-106.

64. Wolmark N, Rockette H, Fisher B, Wickerham DL, Redmond C, Fisher ER, et al. The benefit of leucovorin-modulated fluorouracil as postoperative adjuvant therapy for primary colon cancer: results from National Surgical Adjuvant Breast and Bowel Project protocol C-03. J Clin Oncol. 1993;11(10):1879-87.

65. Saltz LB, Douillard JY, Pirotta N, Alakl M, Gruia G, Awad L, et al. Irinotecan plus fluorouracil/leucovorin for metastatic colorectal cancer: a new survival standard. Oncologist. 2001;6(1):81-91.

66. Emmanouilides C, Sfakiotaki G, Androulakis N, Kalbakis K, Christophylakis C, Kalykaki A, et al. Front-line bevacizumab in combination with oxaliplatin, leucovorin and 5-fluorouracil (FOLFOX) in patients with metastatic colorectal cancer: a multicenter phase II study. BMC Cancer. 2007;7:91.

67. Fuchs CS, Marshall J, Mitchell E, Wierzbicki R, Ganju V, Jeffery $\mathrm{M}$, et al. Randomized, controlled trial of irinotecan plus infusional, bolus, or oral fluoropyrimidines in first-line treatment of 
metastatic colorectal cancer: results from the BICC-C Study. J Clin Oncol. 2007;25(30):4779-86.

68. Loupakis F, Cremolini C, Masi G, Lonardi S, Zagonel V, Salvatore $\mathrm{L}$, et al. Initial therapy with FOLFOXIRI and bevacizumab for metastatic colorectal cancer. N Engl J Med. 2014;371(17):1609-18.

69. Venook AP, Niedzwiecki D, Lenz HJ, Innocenti F, Fruth B, Meyerhardt JA, et al. Effect of first-line chemotherapy combined with cetuximab or bevacizumab on overall survival in patients with KRAS wild-type advanced or metastatic colorectal cancer: a randomized clinical trial. JAMA. 2017;317(23):2392-401.

70. Heinemann V, von Weikersthal LF, Decker T, Kiani A, VehlingKaiser U, Al-Batran S-E, et al. FOLFIRI plus cetuximab versus FOLFIRI plus bevacizumab as first-line treatment for patients with metastatic colorectal cancer (FIRE-3): a randomised, openlabel, phase 3 trial. Lancet Oncol. 2014;15(10):1065-75.

71. Peeters M, Price TJ, Cervantes A, Sobrero AF, Ducreux M, Hotko Y, et al. Randomized phase III study of panitumumab with fluorouracil, leucovorin, and irinotecan (FOLFIRI) compared with
FOLFIRI alone as second-line treatment in patients with metastatic colorectal cancer. J Clin Oncol. 2010;28(31):4706-13.

72. Douillard JY, Siena S, Cassidy J, Tabernero J, Burkes R, Barugel $\mathrm{M}$, et al. Randomized, phase III trial of panitumumab with infusional fluorouracil, leucovorin, and oxaliplatin (FOLFOX4) versus FOLFOX 4 alone as first-line treatment in patients with previously untreated metastatic colorectal cancer: the PRIME study. J Clin Oncol. 2010;28(31):4697-705.

73. La hospitalización en el Sistema Nacional de Salud CMBD—Registro de altas. Informe resumen 2010. Información y estadísticas sanitarias 2012 [online database]. https://www.mscbs.gob.es/estad Estudios/estadisticas/docs/Hospitalizacion_SNS_CMBD_Infor me2010.pdf. Accessed 8 Jan 2018.

74. ICO. Institut Català d'Oncologia. Informe per a la comissió de farmàcia i terapèutica ICO i la sub-comissió de càncer de l'ICS. Cetuximab y bevacizumab. Cáncer colorrectal metastásico (CCRm) 1 1 línea. 2016.

75. ICO. Institut Català d'Oncologia. Informe per a la comissió de farmàcia i terapèutica ICO. Panitumumab vs cetuximab. Càncer colorectal metastàsic (CCRm). 2010.

\section{Affiliations}

\section{Sherley Diaz-Mercedes ${ }^{1}$ (1) - Ivan Archilla ${ }^{1} \cdot$ Jordi Camps ${ }^{2,8} \cdot$ Antonio de Lacy $^{3} \cdot$ Iñigo Gorostiaga ${ }^{4}$ - Dulce Momblan ${ }^{3}$.

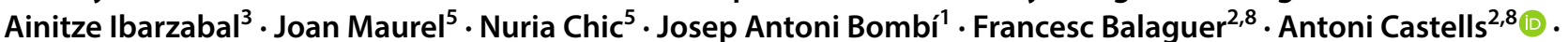 Iban Aldecoa ${ }^{1,6}\left([) \cdot\right.$ Josep Maria Borras ${ }^{7} \cdot$ Miriam Cuatrecasas ${ }^{1,4,8}(1)$}

1 Pathology Department-Center of Biomedical Diagnosis (CDB), Hospital Clínic, University of Barcelona, Villarroel 170, 08036 Barcelona, Spain

2 Gastroenterology Department, Hospital Clinic, University of Barcelona, IDIBAPS, CIBERehd, Barcelona, Spain

3 Surgical Department, Hospital Clinic, Barcelona, Spain

4 Pathology Department, Araba University Hospital, Vitoria-Gasteiz, Spain

5 Medical Oncology Department, Hospital Clinic of Barcelona, Translational Genomics and Targeted Therapeutics in Solid Tumors Group, IDIBAPS, University of Barcelona, Barcelona, Spain
6 Neurological Tissue Bank of the Biobank Clinic-IDIBAPS-XBTC, Hospital Clinic, Barcelona, Spain

7 Department of Clinical Sciences and Bellvitge Biomedical Research Institute (IDIBELL), Universitat de Barcelona, Barcelona, Spain

8 CIBERehd and Banc de Tumors-Biobanc Clinic-IDIBAPS-XBTC, Hospital Clinic, Barcelona, Spain 